\title{
AVALIAÇÃO DO EFEITO DE BENTAZONA COMO ANTÍDOTO A HERBICIDAS APLICADOS EM MILHO E CAPIM SUDÃO
}

\author{
Paulo Ricardo Ebert Siqueira ${ }^{1 ;}$ Lucas da Luz Soares², Gabriel Sanches Comin², \\ 'Eng. Agrônomo Professor Doutor, Agronomia, URCAMP ; ${ }^{2}$ Acadêmico de Agronomia, URCAMP
}

\begin{abstract}
RESUMO: A produção e a qualidade dos cultivos de milho e do capim sudão podem ser reduzidos por plantas indesejáveis. O controle dessas plantas pode ser feita mediante o emprego de herbicidas, mas alguns podem causar injúrias nos cultivos. Assim, o emprego de antídotos é uma técnica que objetiva aumentar a tolerância das culturas à utilização de herbicidas. Desse modo, objetivou-se avaliar o efeito do herbicida Bentazona nas culturas de milho e de capim sudão pulverizadas em pós emergência com os herbicidas Atrazina, Imazetapir e S-Metolacloro. Imazetapir de forma isolada e em associação com Bentazona promoveu a morte das plantas de milho e de capim sudão, não sendo viável o emprego deste herbicida para tais espécies. Nenhum efeito protetor da Bentazona foi identificado para as culturas, herbicidas e modalidade de emprego testada. Apesar das injúrias causadas os herbicidas Atrazina e S-Metolacloro não afetaram de forma significativa a produção de matéria seca das culturas testadas.
\end{abstract}

Palavras-chave: Protetores de plantas, fitotoxicidade, controle de plantas daninhas

\section{EVALUATION OF BENTAZONE EFFECT AS SAFENER TO HERBICIDES APPLIED ON MAIZE AND SUDANGRASS}

ABSTRACT: Crop quality and production might be reduce by weed plants in maize and sudangrass. The control of these plants in crops can be made through herbicides, but some might injure crops. Thus safeners is a technique that aims to increase the tolerance of crops to the use herbicides. Therefore, aimed to evaluate the effect of Bentazone herbicide on maize and sudangrass crops sprayed in postemergence with Atrazine, Imazethapyr, and S-Metolachlor herbicides. Imazethapyr alone and in association with Bentazone promoted the death of maize and sudangrass plants, it not been feasible the employment of this herbicide for such species. No Bentazone protective effect was identified for crops, herbicides, and 
tested employment mode. Despite of injuries caused by Atrazine and S-Metolachlor herbicides did not significantly affect the dry matter production of the tested crops.

Keywords: plant protectors, phytotoxicity, weed control

\section{INTRODUÇÃO}

A interferência das plantas indesejáveis nas culturas destinadas à produção de grãos, silagem ou pastejo é expressiva em decorrência da competição, redução da qualidade disponibilizada para colheita, baixo consumo dos rebanhos pela presença de componentes vegetais de baixo valor alimentício e toxidez.

Levantamentos de redução da produtividade nas lavouras recentemente realizados na Índia verificaram que são perdidos anualmente em decorrência da interferência de plantas daninhas $25,3 \%$ da produção do milho e $25,1 \%$ na cultura do sorgo (GHARDE et al., 2018). No Brasil, diversos trabalhos de pesquisa com a cultura do milho avaliaram as reduções causadas por plantas daninhas e diferentes percentuais de perda da produção foram encontrados, como $15 \%$ verificados por Kozlowski et al. (2009) e 21,8\% (DUARTE et al., 2002). Também, na cultura do sorgo constataram reduções causadas por plantas daninhas variando de $19,5 \%$ (CABRAL et al., 2013) até 89,6\% (RODRIGUES et al., 2010). Uma das formas mais empregadas para a supressão da interferência das plantas indesejáveis é através da utilização de herbicidas. Tais substâncias objetivam interferir no metabolismo das plantas alvo do controle, debilitando-as e na medida do possível levando-as até morte. Por outro lado, o efeito deletério dos herbicidas sobre a cultura deve ser o mínimo possível a fim de não comprometer a mesma.

O milho Zea mays L. é o cereal com a segunda maior área de cultivo mundial e ocupou, na safra 2018/2019, um total de 184 milhões de hectares, superado apenas pelo trigo (USDA, 2018), enquanto no Brasil, na mesma safra o milho ocupou 17,5 milhões de hectares sendo superado somente pela soja (CONAB, 2018).

O capim sudão Sorghum sudanense (Piper) Stap, por sua vez, é uma gramínea forrageira estival adaptada tanto às condições tropicais como às semiáridas (AWAD et al. 2013). Além do emprego forrageiro, S. sudanense 
apresenta características favoráveis para emprego como cultura de cobertura do solo com ênfase à semeadura direta de lavouras anuais (BORGES et al., 2015).

No Brasil estão registrados para uso após a semeadura da cultura do sorgo granífero Sorghum bicolor (L.) Moench, os herbicidas Atrazina, Simazina e 2.4D, todavia não há atualmente nenhum herbicida registrado para uso no capim sudão no país (AGROFIT, 2018). Diante de tal cenário inexistem alternativas registradas para o controle químico de plantas indesejáveis nas áreas cultivadas com S. sudanense e o presente trabalho objetivou testar diferentes herbicidas, registrados para outras culturas, para aplicação nesta cultura com e sem o suposto efeito de Bentazona como antídoto.

Os antítodos, também referidos como protetores ou ainda safeners, são substâncias empregadas para reduzir a fitotoxicidade dos herbicidas por processos fisiológicos e/ou moleculares sem comprometer o controle das plantas indesejáveis (SILVA et al., 2014). A maior parte dos antídotos é veiculada via tratamento de sementes e, um número limitado é empregado na cultura já emergida.

Vários protetores apresentam similaridade aos herbicidas aos quais se objetiva empregar na cultura e exercem ação nos mesmos sítios bioquímicos nos quais estes exercem sua atividade, todavia reduzindo a fitotoxicidade e, em vários casos, até herbicidas são empregados como safeners (ZHAO et al., 2019).

Para a cultura do milho são reconhecidos como protetores a herbicidas Carbamatos e Cloroacetamidas os antídotos MG 191 e PPG 1292 e, como protetores do sorgo aos herbicidas Alachlor e Acetochlor o antídoto Flurazole e ao Metolacloro o antídoto CGA 133205 (OLIVEIRA JÚNIOR et al., 2011).

Quanto à cultura do milho, com diversas alternativas de herbicidas disponíveis, objetivou-se testar o herbicida Imazetapir sem registro para a mesma e os efeitos de Bentazona como antídoto para herbicidas.

\section{MATERIAL E MÉTODO}

Pesquisa realizada no Campus do Curso de Agronomia da URCAMP

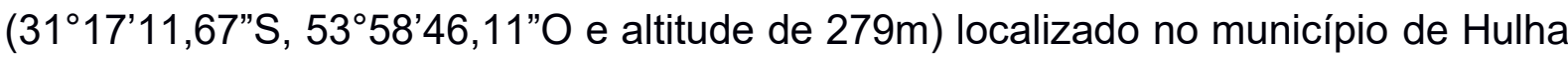
Negra, na Região da Campanha do Estado do Rio Grande do Sul. Experimento conduzido no campo, de Janeiro a Março de 2018 em solo Luvissolo Háplico Órtico 
típico Streck et al. (2008), com delineamento de blocos ao acaso com quatro repetições. Cada repetição consistiu de uma fileira com três metros de comprimento, sendo empregadas por parcela 14 sementes de milho e 40 sementes de sorgo. Após a emergência das plantas e previamente à aplicação dos tratamentos foram escolhidas em cada parcela 8 plantas saudáveis e bem desenvolvidas para serem conservadas para fins de avaliação. Estas plantas foram identificadas com estaquinhas de madeira afixadas ao lado. Utilizou-se variedade de capim sudão BRS Estribo e o híbrido de milho 30A77PW para receberem os tratamentos. Foram testados os seguintes tratamentos nas respectivas dosagens de ingrediente ativo por hectare:

1) Atrazina $2,5 \mathrm{Kg}$; 2) Atrazina $2,5 \mathrm{Kg}$ + Bentazona $0,72 \mathrm{Kg}$; 3) S-Metolacloro 1,68Kg; 4) S-Metolacloro $1,68 \mathrm{Kg}$ + Bentazona $0,72 \mathrm{Kg}$; 5) Imazetapir $0,1 \mathrm{Kg}$; 6) Imazetapir $0,1 \mathrm{Kg}$ + Bentazona $0,72 \mathrm{Kg}$ e; 7) Testemunha sem receber herbicidas.

A aplicação foi realizada com pulverizador costal equipado com pontas do tipo cone vazio e com válvula reguladora de pressão e vazão, selecionada para a pressão de 2,0 Bar e volume de calda de 100L por hectare.

No dia da aplicação dos tratamentos foi realizada a contagem do número de folhas já distendidas por planta e a altura das plantas, cuja medição foi realizada desde a superfície do solo até a extremidade da maior das folhas estendida na vertical, com emprego de uma régua de madeira. Na mesma ocasião ocorreu a verificação de alguma eventual injúria prévia nas plantas de modo a evitar confusão com os sintomas causados pelos herbicidas a serem aplicados.

Para a avaliação e determinação da intensidade de fitotoxicidade causada pelos herbicidas foi empregada a escala da EWRC (1964), constante na Tabela 1.

O dia da aplicação foi considerado 0 DAT (zero dia após o tratamento). As mesmas avaliações (número de folhas, altura das plantas e grau de injúria) foram realizadas aos 3, 7, 15 e 30 DAT. Em todas as avaliações, o número de folhas, altura das plantas e grau de injúria foram atribuidos sempre às mesmas oito plantas, previamente identificadas, objetivando maior acurácia da avaliação.

Para determinar a produção de massa verde produzida por planta, foram colhidas a primeira, a terceira e a quinta plantas de cada unidade experimental no sentido Leste-Oeste. Para a colheita as plantas foram cortadas a cinco centímetros 
da superfície do solo e acondicionadas em sacos plásticos. O material colhido foi pesado em balança eletrônica de precisão e conservado resfriado até ser determinada a matéria seca em estufa de ar forçado à temperatura de $65^{\circ} \mathrm{C}$.

Tabela 1. Índice de avaliação de fitotoxicidade. EWRC (1964).

\begin{tabular}{ll}
\hline Índice de fitotoxicidade & Descrição \\
\hline 1 & Danos ausentes. \\
3 & Alterações leves e em poucas plantas, clorose e deformidade. \\
4 & Clorose acentuada ou deformidade moderada, necrose ausente. \\
5 & Necrose parcial, deformidades nas folhas e brotos. \\
6 & Necrose acentuada, encarquilhamento e redução no porte. \\
7 & Morte de mais de 80\% das folhas. \\
8 & Injúrias graves, pouca área foliar verde. \\
9 & Morte da planta.
\end{tabular}

As plantas de milho foram colhidas 41 dias após a aplicação dos tratamentos e as de capim sudão aos 57 dias após os tratamentos.

Os resultados foram analisados pelo teste $F$, com a comparação das médias pelo teste de Tukey, ao nível de 5\% de probabilidade, utilizando-se do programa Statistica for Windows v.7.

\section{RESULTADOS}

O número de folhas nas plantas de milho não apresentou diferenças significativas entre os diferentes tratamentos aos 3 DAT, entretanto aos 7 , aos $15 \mathrm{e}$ aos 30 DAT as plantas tratadas com imazetapir e com imazetapir + bentazona apresentaram número de folhas inferior aos demais tratamentos (Tabela 2).

Com relação ao efeito dos tratamentos na altura do milho, não ocorreram diferenças significativas aos 3DAT. Já aos 7 DAT as plantas do tratamento testemunha, sem receber herbicidas foram as mais altas, sem diferir significativamente dos tratamentos atrazina e atrazina + bentazona e, aos 15 DAT, as plantas dos tratamentos imazetapir e imazetapir + bentazona foram 
significativamente menores às dos demais tratamentos, o que se repetiu aos 30DAT (Tabela 3).

Tabela 2. Número de folhas por planta em plantas de milho submetidas a diferentes tratamentos herbicidas aos 0, 3, 7, 15 e 30 dias após o tratamento (DAT). Bagé-RS, 2018.

\begin{tabular}{|c|c|c|c|c|c|}
\hline Tratamentos & 0 DAT & 3 DAT & 7 DAT & 15 DAT & 30 DAT \\
\hline & & $5,81 \pm$ & & & \\
\hline Atrazina & $5,00 \pm 0,00^{*}$ n.s. & 0,08n.s. & $7,13 \pm 0,16 a$ & $8,88 \pm 0,22 a$ & $12,56 \pm 0,51 a$ \\
\hline Atrazina + Bentazona & $5,19 \pm 0,12$ & $5,72 \pm 0,16$ & $6,75 \pm 0,21 a$ & $8,97 \pm 0,16 a$ & $12,78 \pm 0,29 a$ \\
\hline S-Metolacloro & $5,25 \pm 0,16$ & $5,66 \pm 0,06$ & $6,72 \pm 0,22 a$ & $8,22 \pm 0,46 a$ & $11,97 \pm 0,48 a$ \\
\hline $\begin{array}{l}\text { S-Metolacloro + } \\
\text { Bentazona }\end{array}$ & $5,25 \pm 0,07$ & $5,69 \pm 0,13$ & $6,68 \pm 0,15 a$ & $8,48 \pm 0,70 a$ & $11,98 \pm 0,84 a$ \\
\hline Imazetapir & $5,09 \pm 0,16$ & $5,50 \pm 0,16$ & $5,63 \pm 0,22 b$ & $4,69 \pm 0,23 b$ & $2,67 \pm 1,56 b$ \\
\hline $\begin{array}{l}\text { Imazetapir + } \\
\text { Bentazona }\end{array}$ & $5,38 \pm 0,16$ & $5,66 \pm 0,28$ & $5,44 \pm 0,08 b$ & $4,84 \pm 0,21 b$ & $5,00 \pm 1,83 b$ \\
\hline Testemunha & $5,28 \pm 0,11$ & $6,22 \pm 0,18$ & $7,31 \pm 0,19 a$ & $8,66 \pm 0,45 a$ & $12,86 \pm 0,45 a$ \\
\hline
\end{tabular}

Foi observado que aos 3 DAT com exceção do tratamento Atrazina, todas as plantas apresentaram sintomas de fitotoxicidade em graus que diferiram significativamente da testemunha (Tabela 4). Aos 7 DAT todos os tratamentos herbicidas apresentaram graus de fitotoxicidade significativamente superiores à testemunha e o tratamento Atrazina nesta oportunidade foi menos fitotóxico que os demais herbicidas (Tabela 4).

Tabela 3. Altura das plantas de milho $(\mathrm{cm})$ submetidas a diferentes tratamentos herbicidas aos $0,3,7,15$ e 30 dias após o tratamento (DAT). Bagé-RS, 2018.

\begin{tabular}{|c|c|c|c|c|c|}
\hline Tratamentos & $0 \mathrm{DAT}$ & 3 DAT & 7 DAT & 15 DAT & 30 DAT \\
\hline Atrazina & $\begin{array}{r}32,23 \pm \\
1,71^{*} \text { n.s. }\end{array}$ & $\begin{array}{l}39,44 \pm \\
1,44 \text { n.s. }\end{array}$ & $50,06 \pm 2,04 a b$ & $72,88 \pm 3,38 a$ & $110,59 \pm 3,66 a$ \\
\hline Atrazina + Bentazona & $32,09 \pm 2,20$ & $37,81 \pm 2,67$ & $\begin{array}{l}45,63 \pm \\
2,23 a b c\end{array}$ & $69,50 \pm 1,59 a$ & $109,69 \pm 1,95 a$ \\
\hline S-Metolacloro & $34,84 \pm 2,16$ & $38,31 \pm 2,43$ & $43,72 \pm 2,70 \mathrm{bc}$ & $60,47 \pm 2,72 a$ & $94,25 \pm 4,27 a$ \\
\hline $\begin{array}{l}\text { S-Metolacloro + } \\
\text { Bentazona }\end{array}$ & $33,86 \pm 2,34$ & $37,84 \pm 1,57$ & $43,66 \pm 1,81 b c$ & $62,92 \pm 4,90 a$ & $98,11 \pm 9,38 a$ \\
\hline Imazetapir & $33,94 \pm 2,36$ & $35,94 \pm 2,29$ & $35,59 \pm 2,32 c$ & $33,67 \pm 2,88 b$ & $16,67 \pm 8,92 b$ \\
\hline $\begin{array}{l}\text { Imazetapir + } \\
\text { Bentazona }\end{array}$ & $34,16 \pm 3,06$ & $36,09 \pm 3,28$ & $35,91 \pm 3,18 c$ & $35,25 \pm 3,15 b$ & $31,46 \pm 10,76 b$ \\
\hline Testemunha & $35,58 \pm 1,73$ & $44,84 \pm 1,55$ & $56,06 \pm 2,52 a$ & $75,31 \pm 4,69 a$ & $110,41 \pm 5,84 a$ \\
\hline
\end{tabular}

Médias seguidas por letras distintas nas colunas diferem entre si pelo teste de Tukey $(p<0,05)$. ${ }^{*}$.s. = não significarivo. 
Decorridos 15 DAT o tratamento Atrazina não diferiu da testemunha enquanto os demais tratamentos apresentaram graus de fitotoxicidade superiores à testemunha. Os tratamentos Imazetapir e Imazetapir + Bentazona foram os mais injuriantes às plantas de milho aos 15 DAT (Tabela 4).

Aos 30 DAT todos os tratamentos causaram graus de injúrias superiores à testemunha, sendo os tratamentos Atrazina e Atrazina + Bentazona os que promoveram danos menores e, os mais injuriantes Imazetapir e Imazetapir + Bentazona.

Tabela 4. Notas de fitotoxicidade em plantas de milho submetidas a diferentes tratamentos herbicidas aos 3, 7 , 15 e 30 dias após o tratamento (DAT). Bagé-RS, 2018.

\begin{tabular}{|c|c|c|c|c|}
\hline Tratamentos & 3 DAT & 7 DAT & 15 DAT & 30 DAT \\
\hline Atrazina & $2,81 \pm 0,77^{\star} a b$ & $2,94 \pm 0,32 b$ & $2,91 \pm 0,59 a b$ & $2,19 \pm 0,26 b$ \\
\hline Atrazina + Bentazona & $5,06 \pm 0,38 \mathrm{~cd}$ & $5,13 \pm 0,51 c$ & $3,50 \pm 0,61 b c$ & $2,19 \pm 0,11 b$ \\
\hline S-Metolacloro & $6,13 \pm 0,54 d$ & $6,16 \pm 0,29 c$ & $4,09 \pm 0,55 b c$ & $3,28 \pm 0,14 c$ \\
\hline $\begin{array}{l}\text { S-Metolacloro + } \\
\text { Bentazona }\end{array}$ & $5,97 \pm 0,40 d$ & $6,11 \pm 0,35 c$ & $5,18 \pm 0,50 c$ & $2,77 \pm 0,13 b c$ \\
\hline Imazetapir & $3,50 \pm 0,23 b c$ & $6,56 \pm 0,34 c$ & $8,13 \pm 0,22 d$ & $8,78 \pm 0,18 d$ \\
\hline Imazetapir + Bentazona & $3,72 \pm 0,63 b c$ & $6,44 \pm 0,15 c$ & $8,06 \pm 0,06 d$ & $8,66 \pm 0,14 d$ \\
\hline Testemunha & $1,00 \pm 0,00 a$ & $1,00 \pm 0,00 a$ & $1,00 \pm 0,00 a$ & $1,00 \pm 0,00 a$ \\
\hline
\end{tabular}

Foi verificado que as plantas de milho expostas aos herbicidas, com exceção daquelas que foram pulverizadas com Imazetapir e Imazetapir + Bentazona (e morreram), apesar de apresentarem injúrias superiores ao tratamento testemunha aos 30 DAT (Tabela 4) produziram quantidade de matéria verde e de matéria seca estatisticamente equivalente às plantas não pulverizadas (Tabela 5).

De modo semelhante ao observado no milho, as plantas de capim sudão expostas aos herbicidas, com exceção daquelas mortas por Imazetapir e Imazetapir + Bentazona, apesar de apresentarem injúrias superiores ao tratamento testemunha aos 30 DAT (Tabela 8) produziram quantidade de matéria verde estatisticamente equivalente à testemunha (Tabela 5). Com relação à matéria seca produzida por $S$. sudanense, os tratamentos com herbicidas não diferiram entre si, enquanto 0 tratamento testemunha superou de forma significativa os tratamentos Imazetapir e Imazetapir + Bentazona, sem diferir dos demais (Tabela 5) 
Tabela 5. Produção de massa verde MV (gramas por planta) e de matéria seca MS (grama por planta) em plantas de milho e sorgo submetidas a diferentes tratamentos herbicidas. Bagé-RS, 2018.

\begin{tabular}{|c|c|c|c|c|}
\hline \multirow{2}{*}{ Tratamentos } & \multicolumn{2}{|c|}{ Milho } & \multicolumn{2}{|c|}{ Sorgo } \\
\hline & $\mathrm{MV}$ & MS & $\mathrm{MV}$ & MS \\
\hline Atrazina & $338,67 \pm 40,16 a$ & $64,16 \pm 7,91 \mathrm{a}$ & $243,25 \pm 56,56 a$ & $67,14 \pm 16,47 \mathrm{ab}$ \\
\hline Atrazina + Bentazona & $368,08 \pm 65,44 a$ & $75,14 \pm 12,95 a$ & $149,25 \pm 50,95 a b$ & $32,80 \pm 12,49 a b$ \\
\hline S-Metolacloro & $237,25 \pm 40,77 a$ & $43,90 \pm 7,29 a$ & $156,17 \pm 54,42 a b$ & $38,38 \pm 11,24 a b$ \\
\hline S-Metolacloro + Bentazona & $237,92 \pm 58,81 a$ & $42,35 \pm 12,09 a$ & $150,75 \pm 47,74 a b$ & $46,85 \pm 17,24 a b$ \\
\hline Imazetapir & $0,00 \pm 0,00 b$ & $0,00 \pm 0,00 b$ & $0,00 \pm 0,00 b$ & $0,00 \pm 0,00 b$ \\
\hline Imazetapir + Bentazona & $0,00 \pm 0,00 b$ & $0,00 \pm 0,00 b$ & $0,00 \pm 0,00 b$ & $0,00 \pm 0,00 \mathrm{~b}$ \\
\hline Testemunha & $300,92 \pm 31,12 a$ & $55,92 \pm 7,27 a$ & $369,00 \pm 87,29 a$ & $98,91 \pm 34,67 a$ \\
\hline
\end{tabular}

No capim sudão, aos 3 DAT à exceção de Atrazina e S-Metolacloro os demais tratamentos reduziram 0 incremento de novas folhas e desse modo 0 número destas estruturas fotossintética foi significativamente menor ao das plantas testemunhas (Tabela 6).

Aos 7 DAT todos os herbicidas reduziram o número de folhas em relação à testemunha, com destaque a Imazetapir e Imazepapir + Bentazona, cujas fortes injúrias apresentaram redução do número das folhas em relação ao existente previamente ao uso dos herbicidas (Tabela 6).

Tabela 6. Número de folhas por planta em plantas de capim sudão submetidas a diferentes tratamentos herbicidas aos 0, 3, 7, 15 e 30 dias após o tratamento (DAT). Bagé-RS, 2018.

\begin{tabular}{|c|c|c|c|c|c|}
\hline Tratamentos & 0 DAT & 3 DAT & 7 DAT & 15 DAT & 30 DAT \\
\hline Atrazina & $3,84 \pm 0,09^{*}$ n.s. & $5,63 \pm 0,41 a b$ & $6,61 \pm 0,76 b$ & $16,00 \pm 2,52 a$ & $34,46 \pm 3,32 a$ \\
\hline Atrazina + Bentazona & $3,94 \pm 0,11$ & $4,69 \pm 0,34 b$ & $6,13 \pm 0,89 b c$ & $12,83 \pm 2,45 a$ & $32,77 \pm 8,75 a$ \\
\hline S-Metolacloro & $3,94 \pm 0,32$ & $5,59 \pm 0,57 a b$ & $7,47 \pm 0,71 b$ & $14,56 \pm 2,13 a$ & $31,01 \pm 5,16 a$ \\
\hline $\begin{array}{l}\text { S-Metolacloro + } \\
\text { Bentazona }\end{array}$ & $4,09 \pm 0,25$ & $5,02 \pm 0,55 b$ & $6,49 \pm 1,04 b c$ & $17,02 \pm 1,81 a$ & $27,28 \pm 2,48 a$ \\
\hline Imazetapir & $4,07 \pm 0,16$ & $5,25 \pm 0,49 b$ & $2,92 \pm 0,34 \mathrm{~cd}$ & $0,00 \pm 0,00 b$ & $0,00 \pm 0,00 b$ \\
\hline Imazetapir + Bentazona & $3,63 \pm 0,09$ & $4,94 \pm 0,19 b$ & $1,63 \pm 0,94 d$ & $0,00 \pm 0,00 b$ & $0,00 \pm 0,00 b$ \\
\hline Testemunha & $3,88 \pm 0,15$ & $7,50 \pm 0,59 a$ & $11,94 \pm 0,73 a$ & $20,53 \pm 1,46 a$ & $34,55 \pm 3,62 a$ \\
\hline
\end{tabular}

Já aos 15 DAT e também aos 30 DAT, os tratamentos Imazetapir e Imazepapir + Bentazona apresentaram a morte de todas as folhas e deterioração Revista Científica Rural, Bagé-RS, volume22, $n^{\circ 2}$, ano 2020 Submetido 08/09/2019. Aceito 01/10/2020 Doi: https://doi.org/10.30945/rcr-v22i2.2662 
das mesmas. Estes tratamentos diferiram da testemunha e dos demais, que não apresentaram diferenças significativas entre si (Tabela 6).

Foi verificado aos 3 DAT que a adição de Bentazona reduziu a altura das plantas de capim sudão de forma significativa em relação à testemunha, fato não verificado quando os demais herbicidas foram usados sem a associação do mesmo (Tabela 7). Aos 7 DAT a altura das plantas do tratamento testemunha foi significativamente superior aos tratamentos com herbicidas, exceto ao SMetolacloro. (Tabela 7).

Decorridos 15 DAT ocorreu a morte e deterioração das plantas nos tratamentos com Imazetapir e Imazetapir + Bentazona. Nessa oportunidade a altura das plantas na testemunha foi superior aos tratamentos com herbicidas, situação que se repetiu aos 30 DAT (Tabela 7 ).

Tabela 7. Altura das plantas de capim sudão $(\mathrm{cm})$ submetidas a diferentes tratamentos herbicidas aos $0,3,7,15$ e 30 dias após o tratamento (DAT). Bagé-RS, 2018.

\begin{tabular}{|c|c|c|c|c|c|}
\hline Tratamentos & 0 DAT & 3 DAT & 7 DAT & 15 DAT & $30 \mathrm{DAT}$ \\
\hline Atrazina & $16,13 \pm 2,40^{*}$ n.s. & $\begin{array}{l}20,66 \pm \\
2,97 \mathrm{ab}\end{array}$ & $24,35 \pm 3,36 b$ & $36,79 \pm 8,94 b$ & $\begin{array}{l}74,00 \pm \\
19,18 b\end{array}$ \\
\hline Atrazina + Bentazona & $17,75 \pm 0,54$ & $19,09 \pm 1,24 b$ & $22,44 \pm 2,28 b$ & $36,06 \pm 4,83 b$ & $32,77 \pm 5,61 b$ \\
\hline S-Metolacloro & $18,53 \pm 0,32$ & $\begin{array}{l}21,89 \pm \\
3,05 a b\end{array}$ & $\begin{array}{l}26,93 \pm \\
4,08 a b\end{array}$ & $39,75 \pm 6,75 b$ & $\begin{array}{l}31,01 \pm \\
11,66 b\end{array}$ \\
\hline $\begin{array}{l}\text { S-Metolacloro + } \\
\text { Bentazona }\end{array}$ & $17,23 \pm 0,25$ & $18,75 \pm 1,26 b$ & $21,81 \pm 2,50 b$ & $36,27 \pm 3,57 b$ & $27,28 \pm 2,17 b$ \\
\hline Imazetapir & $26,81 \pm 0,16$ & $\begin{array}{l}21,12 \pm \\
3,53 \mathrm{ab}\end{array}$ & $20,56 \pm 3,00 b$ & $0,00 \pm 0,00 c$ & $0,00 \pm 0,00 c$ \\
\hline $\begin{array}{l}\text { Imazetapir + } \\
\text { Bentazona }\end{array}$ & $16,00 \pm 0,09$ & $17,28 \pm 1,28 b$ & $11,25 \pm 6,50 b$ & $0,00 \pm 0,00 c$ & $0,00 \pm 0,00 c$ \\
\hline Testemunha & $22,53 \pm 0,15$ & $30,88 \pm 2,81 a$ & $43,81 \pm 3,06 a$ & $61,22 \pm 2,63 a$ & $\begin{array}{c}118,75 \pm \\
3,10 a\end{array}$ \\
\hline
\end{tabular}

Com relação às injúrias dos herbicidas observadas no capim sudão, aos 3 DAT somente o tratamento Atrazina apresentou grau de injúria comparável às plantas do tratamento testemunha, porém aos 7 DAT todos tratamentos apresentaram graus de injúrias superiores à testemunha, com maior gravidade nos tratamentos Atrazina + Bentazona, Imazetapir e Imazetapir + Bentazona (Tabela 8). Decorridos 15 DAT o tratamento Atrazina apresentou grau de injúria comparável à 
testemunha enquanto ocorreu a mortalidade de todas as plantas nos tratamentos Imazetapir e Imazetapir + Bentazona (Tabela 8). Aos 30 DAT todos os tratamentos com herbicidas diferiram da testemunha, apresentando entre estes as menores injúrias Atrazina, S-Metolacloro e S-Metolacloro + Bentazona (Tabela 8).

Tabela 8. Notas de fitotoxicidade em plantas de capim sudão submetidas a diferentes tratamentos herbicidas aos 3, 7, 15 e 30 dias após o tratamento (DAT). Bagé-RS, 2018.

\begin{tabular}{|c|c|c|c|c|}
\hline Tratamentos & 3 DAT & 7 DAT & $15 \mathrm{DAT}$ & 30 DAT \\
\hline Atrazina & $2,94 \pm 0,40 a$ & $6,06 \pm 0,24 b$ & $5,66 \pm 0,56 a b$ & $4,16 \pm 0,64 b$ \\
\hline Atrazina + Bentazona & $7,47 \pm 0,43 c$ & $8,00 \pm 0,21 c$ & $7,09 \pm 0,32 b$ & $6,63 \pm 0,65 c$ \\
\hline S-Metolacloro & $6,93 \pm 0,37 b c$ & $6,60 \pm 0,18 b$ & $6,45 \pm 1,85 b$ & $3,92 \pm 0,74 b$ \\
\hline $\begin{array}{l}\text { S-Metolacloro + } \\
\text { Bentazona }\end{array}$ & $6,36 \pm 0,79 b c$ & $6,62 \pm 0,56 b$ & $7,85 \pm 1,90 b$ & $4,08 \pm 0,28 b$ \\
\hline Imazetapir & $5,06 \pm 0,37 b$ & $8,56 \pm 0,20 c$ & $9,00 \pm 0,00 b$ & $9,00 \pm 0,00 d$ \\
\hline Imazetapir + Bentazona & $6,25 \pm 0,31 b c$ & $8,91 \pm 0,06 c$ & $9,00 \pm 0,00 b$ & $9,00 \pm 0,00 d$ \\
\hline Testemunha & $1,00 \pm 0,00 a$ & $1,00 \pm 0,00 a$ & $1,00 \pm 0,00 a$ & $1,00 \pm 0,00 a$ \\
\hline
\end{tabular}

Médias seguidas por letras distintas nas colunas diferem entre si pelo teste de Tukey $(\mathrm{p}<0,05)$.

No capim sudão o emprego de Atrazina aos 3 DAT promoveu clorose nas folhas sendo que aos 7 DAT e aos 15 DAT foram caracterizadas algumas necroses mas essencialmente a redução no porte das plantas e aos 30 DAT, a redução no porte ainda persistiu, todavia diluindo o efeito necrótico devido ao surgimento de folhas novas e saudáveis.

A mistura de Atrazina + Bentazona causou forte necrose aos 3 DAT, com danos extremos aos 7 DAT e discreta redução dos danos aos 15 e 30 DAT, havendo em todas as oportunidades redução no porte em relação à testemunha (Tabelas 7 e 8). A fitotoxicidade causada por S-Metolacloro e por S-Metolacloro + Bentazona em capim sudão foi muito similar, ambos os tratamentos aos 3 e 7 DAT causaram a necrose próximo a $80 \%$ do tecido foliar, sendo que a mistura foi ainda mais injuriante aos 15 DAT. Todavia aos 30 DAT ocorreu a emissão de novas folhas, livres de injúrias e desta maneira ocorreu a diluição dos sintomas nestes dois tratamentos (Tabela 8).

O herbicida Imazetapir e a mistura de Imazetapir + Bentazona promoveram aos 3 DAT alteração na coloração das plantas de capim sudão as quais apresentaram aspecto arroxeado na bainha foliar na região do colo, além de 
redução do crescimento e da distância entrenós e, clorose muito acentuada no limbo foliar; aos 7 DAT as injúrias foram gravíssimas, evidenciando-se a morte das folhas centrais e necrose de quase todas as folhas, aos 15 DAT todas as plantas estavam mortas e praticamente decompostas.

\section{DISCUSSÃO}

A redução observada no número de folhas nas plantas tratadas com imazetapir em milho (Tabela 2) e capim sudão (Tabela 6) pode ser atribuido ao mecanismo de ação deste herbicida o qual atua inibindo a atividade da enzima Acetolactato Sintetase (ALS) e dessa forma reduz a síntese dos aminoácidos Isoleucina, Leucina e Valina, que irão limitar, por sua vez, a formação de novos tecidos (OLIVEIRA JÚNIOR et al., 2011).

Pesquisas com Imazetapir realizadas por SILVA et al. (1999) constataram que Imazetapir apresenta prolongado efeito residual no solo e decorridos 150 dias da aplicação na lavoura da soja reduziu o porte do milho e do sorgo semeados em sucessão. Já no presente trabalho a aplicação de Imazetapir deu-se sobre as culturas em pós-emergência, uma condição extrema para o milho e o capim sudão, com o objetivo de testar a mistura de Bentazona como antídoto, o que não se verificou, havendo a redução significativa do número de folhas, do porte, além de gravíssimas injúrias que levaram as plantas à morte.

A Atrazina assim como a Bentazona e também o S-Metolacloro não promoveram redução no número de folhas de milho e de capim sudão. A Atrazina pertence ao grupo químico das Triazinas, enquanto a Bentazona ao grupo das Benzotiadiazinonas, sendo que estes dois herbicidas possuem o mesmo mecanismo de ação, a inibição da síntese de Hill, sendo denominados como Inibidores do Fotossistema II enquanto o S-Metolacloro pertence ao grupo das Cloroacetamidas e atua inibindo a divisão celular (OLIVEIRA JÚNIOR et al., 2011). Destes três herbicidas a ação observada nas plantas em condições de aplicações em pós emergência foi principalmente a necrose dos tecidos foliares atingidos pela 
pulverização, sem um maior comprometimento da emissão de novas folhas nas espécies testadas.

A baixa fitotoxicidade observada em milho e moderada em capim sudão, pulverizados com Atrazina, pode ser atribuída à tolerância destas espécies que é decorrência do processo destoxicação dos herbicidas do grupo das Triazinas por meio da ação catalítica da enzima glutationa-S-transferase (SHUKLA; DEVINE, 2008). Pesquisas realizadas em sorgo granífero concluiram que o tratamento das sementes com Fluxofenim apresentou redução da fitotoxicidade quando SMetolacloro foi aplicado na modalidade de pré-emergência da cultura (SILVA et al., 2014).

No presente trabalho verificou-se que o emprego de 1,68 Kg de S-Metolacloro por hectare em pós-emergência da cultura promoveu necrose e forte encarquilhamento no capim sudão já aos 3 DAT, condição que se manteve aos 7 e 15 DAT, somente havendo redução do grau de injúrias ao 30 DAT, devido à emissão de novas folhas, embora muito comprometido o porte das plantas em relação à testemunha (Tabela 7). Verificou-se ainda que, nesta modalidade de emprego, não ocorreu o efeito de Bentazona como antídoto.

Estes resultados divergem dos encontrados por Archangelo et al. (2002) os quais empregaram, em sorgo forrageiro cultivar AG 2002, a dosagem de até 3,6 Kg de S-Metolacloro por hectare em associação à atrazina, sem que ocorressem injúrias severos. Um dos possíveis fatores para esta diferente tolerância deve-se ao fato do sorgo forrageiro em estudo, BRS Estribo ser uma cultivar de $S$. sudanense, enquanto a cultivar AG 2002 ser um híbrido de S. sudanense X S. bicolor, esta última espécie mais tolerante a herbicidas.

Mesmo em sorgo granífero S. bicolor, significativas diferenças foram observadas na África do Sul entre diferentes cultivares semeadas em locais com aplicação em pré-emergência de herbicidas como Atrazine e S-Metolacloro, sendo que as variações genéticas entre as cultivares foram consideradas por aqueles autores como o fator de maior efeito na manifestação da fitotoxicidade, seguido pelo efeito da temperatura do ambiente (SAAYMAN-du TOIT, 2006). 
Outro aspecto a ser considerado é o acentuado efeito das condições ambientais na capacidade dos antídotos reduzirem os níveis de fitotoxicidade dos herbicidas, com significativas variações na ação fitoprotetora observada entre diferentes anos (STEPPIG, 2017).

A forte injúria observada nos tratamentos com Imazetapir, causando a morte de todas as plantas de $S$. sudanense aos 15 DAT, evidencia ser esta espécie altamente sensível ao herbicida. Esta constatação encontra respaldo nas pesquisas de Yu (2014) que observou que decorridos um ano da aplicação deste herbicida na dosagem de $100 \mathrm{~g}$ de ingrediente ativo por hectare, a mesma empregada no presente trabalho, o efeito residual no solo causou injúrias em $28 \%$ da área foliar do sorgo, evidenciando a longa persistência do produto e a sensibilidade da espécie às concentrações residuais.

As severas injúrias, a redução de porte e a mortalidade das plantas de capim sudão causadas pelo emprego de Imazetapir e Imazetapir + Bentazona apresentam similaridade com o observado por Pinto et al. (2009). Estes autores verificaram que S. bicolor semeado em rotação de cultura em lavouras de arroz irrigado pulverizadas com uma mistura comercial com os herbicidas Imazetapir + Imazapic, ambos inibidores da ALS, na safra anterior reduziu severamente a estatura e a população final e concluiram que o sorgo não deve ser empregado em rotação de cultura com lavouras que receberam tal mistura de herbicidas na safra anterior.

No presente trabalho a adição de Bentazona aos herbicidas testados não trouxe vantagens em termos de redução da fitotoxicidade nas plantas de milho (Tabela 4), já no capim sudão percebeu-se que Bentazona aumentou o grau de injúria quando associado à Atrazina aos 3, 7 e 30DAT (Tabela 8). Para os herbicidas testados não se confirmou a redução da fitotoxicidade observada na associação de Bentazona a Saflufenacil verificada por Correia et al. (2014). Diferente dos herbicidas testados no presente estudo, Saflufenacil pertence ao grupo das pirimidinadionas, e atua inibindo a síntese da enzima protoporfirogênio oxidase (OLIVEIRA JÚNIOR, et al., 2011).

\section{CONCLUSÕES}


O milho e o capim sudão são intolerantes ao herbicida Imazetapir.

O herbicida Bentazona não apresenta efeito como antídoto para os herbicidas e culturas testadas em aplicações de pós emergência.

Os herbicidas Atrazina, Atrazina + Bentazona, S-Metolacloro e S-Metolacloro + Bentazona não afetam significativamente a produção de matéria verde e de matéria seca do milho e do capim sudão.

\section{REFERÊNCIAS}

AGROFIT Sistema de Agrotóxicos Fitossanitário. Ministério da Agricultura Pecuária e Abastecimento. Disponível em: <http://agrofit.agricultura.gov.br/agrofit_cons/principal_agrofit_cons> Acesso em: 05 mar. 2018.

ARCHANGELO, E.R.; DA SILVA, A.A.; DA SILVA, J.B. et al. Seletividade e eficácia de herbicidas aplicados em pós emergência na cultura do sorgo forrageiro. Revista Brasileira de Milho e Sorgo, v.1, n.3, p.107-115, 2002.

AWAD, A.; HAFIZ, S.; HAMMADA, M.S. Grain yield production of Sudan grass (Sorghum sudanense (Piper) Stapf) as influenced by cut numbers, potassium rates, and intrarow spacing in a semiarid environment. Turkish Journal of Agriculture and Forestry. v.37, p.657664. 2013.

BORGES, W.L.B.; FREITAS, R.S. de; MATEUS, G.P. et. al. Plantas de cobertura para o noroeste do estado de São Paulo. Ciência Rural, v.45, n.5, p.799-805, 2015.

CABRAL, P.H.R; JAKELAITIS, A.; CARDOSO, I.S. et al. Interferência de plantas daninhas na cultura do sorgo cultivado em safrinha. Pesquisa Agropecuária Tropical. v.43, n.3, p.308314, 2013.

CONAB - COMPANHIA NACIONAL DE ABASTECIMENTO. Acompanhamento da safra brasileira de grãos Safra 2017/2018: décimo primeiro levantamento. v.5, n.11 Brasília: CONAB, 2018. 148p. 2 Disponível em: file://C:/Users/Cliente/Downloads/BoletimZGraosZagostoZ2018.pdf > Acesso em: 27 Ago. 2018.

CORREIA, N.M.; GOMES, L.J.P. Uso de Na-Bentazon como 'Safener' de saflufenacil para sorgo sacarino. In: CONGRESSO BRASILEIRO DA CIÊNCIA DAS PLANTAS DANINHAS, 29., 2014, Gramado, RS. Anais... Londrina: SBCPD, 2014. 5p.

DUARTE, N. De F.; Da SILVA, J.B.; De SOUZA, I.F. Competição de plantas daninhas com a cultura do milho em ljaci, MG. Ciência Agrotécnica, v.26, n.5, p.983-992, 2002.

EUROPEAN WEED RESEARCH COUNCIL - EWRC. Report of the 3th and 4th meetings of EWRC- Comittee of methods in weed research. Weed Research, v.4, n.1, p. 88, 1964. 
GHARDE, Y.; SINGH, P.K.; DUBEY, R.P. et al. Assessment of yield and economic losses in agriculture due to weeds in India. Crop Protection, n.107, p.12-18, 2018.

KOZLOWSKI, L.A.; KOEHLER, H.S.; PITELLI, L.A. Épocas e extensão do período de convivência das plantas daninhas interferindo na produtividade da cultura do milho (Zea mays). Planta Daninha, v.27, n.3, p.484-490, 2009.

OLIVEIRA JÚNIOR, R.S. de; CONSTANTIN, J.; INOUE, M.H. eds. Biologia e Manejo de Plantas Daninhas. Curitiba: OMNIPAX, 2011, 348p.

PINTO, J.J.O.; NOLDIN, J.A.; PINHO, C.F. et al. Atividade residual de (Imazethapyr + Imazapic) para sorgo granífero (Sorghum bicolor) semeado em rotação com arroz irrigado. Planta Daninha, v.27, Número Especial, p.1015-1024, 2009.

RODRIGUES, A.C.P.; COSTA, N.V.; CARDOSO, L.A. et al. Períodos de interferência de plantas daninhas na cultura do sorgo. Planta Daninha, v.28, n.1, p.23-31, 2010.

SAAYMAN-du TOIT, A.E.J. Phytotocity resulting from pre-emergence graminicides on sorghum. South African Journal of Plant and Soil, v.23, n.1, p.54-57, 2006.

SILVA, A.A. da; OLIVEIRA JR, R.S. de; COSTA, E.R. et al. Efeito residual no solo dos herbicidas Imazamox e Imazethapyr para as culturas de milho e sorgo. Planta Daninha, v.17, n.3, p.345-354, 1999.

SILVA, J.R.V. da; MARTINS, C.C.; SILVA JUNIOR, A.C. da et al. Fluxofenim used as a safener on sorghum seed for S-Metolachlor herbicide. Bioscience Journal, v.30, n.1, p.15817, 2014.

SHUKLA, A.; DEVINE, M.D. Basis of crop selectivity and weed resistance to triazine herbicides. In: LEBARON, H.M.; MCFARLAND, J.E.; BURNSIDE, O.C. (ed.) The triazine herbicides: 50 years revolutionizing agriculture. Oxford: Elsevier, 2008. p.111-118.

STRECK, E.V.; KÄMPF, N.; DALMOLIN, R.S.D. Solos do Rio Grande do Sul. 2.ed. Porto Alegre: EMATER/RS, 2008. 220p.

USDA - United State Departament of Agriculture. World Agricultural Production. Foreign Agricultural Series. 34p. Aug. 2018. Disponível em: < http://apps.fas.usda.gov/psdonline/circulars/production.pdf > Acesso em: 27 aug. 2018.

YU, L. Effect of herbicide residues on spring and fall seed cover crops. 2014. $107 f$. Dissertation (Master in Plant Agriculture) - University of Guelph. 